direct use to a British engineer concerned with the design of highway bridges, many of which are prestressed precast beams with in situ infill or topping.

The major disadvantage with the book is that all the worked examples are based on the relevant American standards and codes of practice. These have, of course, been written in Imperial units using a variety of different forms of analysis, whereas British practice is now metricated and tending towards limit-state design. In addition, the absence of a complete list of notation makes the examples hard to follow. However, large sections of the relevant American documents are reproduced in Appendices, thus making it possible for the dedicated reader to follow the logic of the design process, even if the basic philosophy differs from that of British practice.

Taking the book on a whole, it would seem to be more suitable as an introduction to the different forms of composite construction than as a text-book for practising design engineers in this country. Though some chapters do give references to relevant publications, these would not appear to be significantly detailed or easily obtainable; a handbook issued by a manufacturing company in New Jersey nearly thirty years ago is unlikely to feature prominently in many technical libraries.

In conclusion, the book is well illustrated and easily readable, most suitable for an interested layman, but at $£ 16.50$ it does not justify its cost to a design engineer.

J. L. ClARKE

\title{
Plastic analysis of concrete frames
}

with particular reference to limit states design

Milík Tichý and Josef Rákosník

Translation: Dagmar Steinová-Friedová

Published by Collet's (Publishing) Ltd, London and Wellingborough, in co-edition with SNTL, Prague. Type-set, illustrated, hardback. $237 \times 155 \mathrm{~mm}$. pp. 319 . ISBN 056908199 8. Price: $\mathfrak{£} 9.95$

This book, which is concerned with the plastic redistribution of moments in concrete framed structures, is intended for designers and has been translated from the original Czechoslovakian. However, the latter point should not deter British designers from consulting the book, as the authors refer frequently to CP110 and to the 1970 CEB-FIP Recommendations. On the whole the translation is very good, but occasionally technical words have, presumably, been translated literally, e.g. the members of a framed structure are referred to as bars. SI units are used throughout.

In their Foreword, the authors state that "theoretical discussions have been reduced to a bare minimum". In spite of this, the reviewer feels that the theoretical content of the book is greater than that usually encountered in a British 'practical text' and, consequently, that the book would be of interest to students as well as to practising designers.

Chapters 1 to 3 are introductory chapters. Chapter 1 contains a particularly useful list of the terminology used in the book and also discusses, in general terms, moment redistribution. In Chapter 2, the various factors (i.e. moment-curvature relationships, structural form and type of loading) which influence moment redistribution are discussed. Chapter 3 contains a discussion of the various approaches to design, i.e. permissible-stress, ultimate-strength, limit-state and probabilistic methods. The illogicality of modifying the permissible-stress design method to allow for redistribution at ultimate is indicated. In addition, the problem of whether to apply partial safety factors to loads or to their effects is mentioned.

Chapter 4 considers the plastic analysis of statically indeterminate concrete structures and is based very much on the work of Professor A. L. L. Baker. Instability effects are also considered in this chapter.

Chapter 5 considers the application to concrete frames of the bound theorems of limit analysis. It is emphasized that the elastic moment distribution, whether or not redistributed, leads to a lower-bound design. Various methods of limiting the amount of permitted redistribution are discussed, and it is concluded that, on the whole, the CP110 approach is the best for design purposes. Methods of redistribution which consider serviceability requirements are presented also.

The serviceability limit state is considered briefly in Chapter 6, but the adopted approach is that of the CEB-FIP Recommendations rather than of CP110. Hence, this chapter, and in particular the section on crack width, is not directly applicable to British practice.

A considerable number of worked examples are given in Chapter 7. These are in accordance with the 1970 CEB-FIP Recommendations and are thus not of immediate use to a British designer, although the principles involved are, obviously, applicable to British practice. 
Chapter 8 contains a useful summary of the clauses pertinent to plastic analysis extracted from the American, French, British, West German, Danish, Spanish, Portuguese, CEB-FIP and Russian Codes. Tables for the plastic analysis and design of continuous beams are also given.

The book concludes with an extensive list of references, some of which are very recent. As is to be expected, a number of references are Eastern European and will not be familiar to most British readers.

To summarize, it is felt that this book would be of benefit to both practising designers and students, not least because, as mentioned in the Foreword, the authors discuss moment redistribution, not in isolation, but with regard to the deformation properties of structural concrete.

L. A. CLARK 